\title{
Penggunaan Audit Klinis Sebagai Cara Pembelajaran Untuk Meningkatkan Perilaku Peserta Didik PPDS Onkologi Radiasi Periode September 2010-Maret 2011
}

\author{
Fielda Djuita**, Harsono*, Ova Emilia*, Soehartati ** \\ *Fakultas Kedokteran Universitas Gadjah Mada, Yogyakarta \\ **RSUPN Cipto Mangunkusumo, Jakarta
}

\begin{abstract}
Background: Clinical Audit is one of the formative evaluations that conducted to maintain and increase behavior and performance of the Radiation Oncology students, as an effort to maintain radiotherapy services and grant the quality of education.

Objective: To evaluate the role of clinical audit in improving students behaviour.

Method: This was a quasi experimental research time series. We have done audit to the medical record chart of the residences at Policlinic I, II, III and stay at semester 3, 4, 5 in FK UI/RSUPNCM between September 2010 untill December 2011 (TO). Audit have done by the author and one of the lecture. After analised the audit report, the reports were sent to the students one by one through email followed by forwarding it to the lecturer involved in this research. Then we continue the audit by performing the second clinical audit (T1) from January untill March 2011. We used the mean score from the two auditors. The score divided into 4 groups as follows: hospital clinical record, treatment prescription, simulation and planning also evaluation during treatment. After that the author compared the audit score before and after intervention with t test.

Result and Discussion: There were 16 Oncology Radiation students with 163 cases (To) and 156 case (T1) who worked at Policlinic I, II and III. Behavior mean score is 1.9229 (T0), standard deviation 0.0514 and mean score after first intervention is 1.9764, standard deviation 0.0479 with $p=0.006$.

Conclusion: The students behaviors and performance are changed significantly after intervention.
\end{abstract}

Keywords: medical education, radiation oncology, audit clinic, formative evaluation, quality assurance, personal behavior

\begin{abstract}
Abstrak
Latar Belakang: Audit klinis adalah salah satu evaluasi formatif yang dilakukan untuk memelihara, meningkatkan perilaku serta kinerja peserta didik Program Pendidikan Dokter Spesialis Onkologi Radiasi, sebagai upaya memelihara kualitas pelayanan radioterapi dan menjamin mutu pendidikan.

Tujuan: Penelitian ini bertujuan untuk mengevaluasi peran audit klinis pada peningkatan perilaku PPDS Onkologi Radiasi.

Metode: Penelitian ini merupakan kuasi eksperimen serial waktu. Audit Klinis dilakukan terhadap catatan medis yang dikerjakan peserta didik dan berada pada semester 3, 4 dan 5 di FK UI/ RSUPNCM antara September 2010 sampai Desember 2010 (T0). Audit dilakukan oleh peneliti dan satu dosen Onkologi Radiasi. Selanjutnya ditelaah dan dilakukan umpan balik secara individual terhadap peserta didik dengan pengiriman email dan diteruskan kepada dosen yang terlibat penelitian ini. Kemudian dilakukan audit kedua setelah intervensi (T1) pada kurun waktu Januari sampai Maret 2011. Nilai yang digunakan adalah nilai rerata kedua auditor. Nilai perilaku dibagi dalam 4 kelompok yaitu: kelompok catatan Rumah Sakit, kelompok rencana pengobatan, kelompok planning dan simulasi serta kelompok selama pengobatan. Sesudah itu nilai sebelum intervensi dan sesudah intervensi dibandingkan dengan $t$ test.
\end{abstract}

Korespondensi: fielda2000@yahoo.com 
Hasil dan Pembahasan: Didapatkan 16 PPDS Onkologi Radiasi dengan jumlah catatan medis yang dikerjakan sebelum intervensi 163 kasus (TO) dan 156 kasus ( $\mathrm{T}_{\mathrm{p}}$. . Rerata nilai perilaku adalah 1.9229 (T0) dengan standar deviasi 0.0534 dan rerata nilai setelah intervensi pertama adalah 1.9764 dengan simpang baku 0.0514 serta $\mathrm{p}=$ 0.006 .

Kesimpulan: Terdapat perubahan perilaku peserta didik yang bermakna setelah intervensi pembelajaran melalui audit klinis.

Kata Kunci: pendidikan kedokteran, onkologi radiasi, audit klinis, evaluasi formatif, kendali mutu, perilaku perseorangan

\section{LATAR BELAKANG}

Menurut Departemen Kesehatan Republik Indonesia, perkiraan angka penderita kanker di Indonesia adalah 100 per 100.000 penduduk. Bila jumlah penduduk Indonesia adalah 230 juta, diperkirakan 230.000 kasus baru ditemukan setiap tahun. Lebih jauh akan terjadi peningkatan tajam dari 10 juta kasus kanker baru pada tahun 2000 menjadi 15 juta pada tahun 2020. ${ }^{1}$ Hampir dua per tiga pasien-pasien kanker akan mendapat radiasi dalam pengobatannya. Di Amerika sekitar 75\% pasien kanker mendapat radiasi sebagai terapi utama.

Berdasarkan data dari American Society Therapeutic Radiation Organisation sekitar 66\% pasien kanker memerlukan radiasi selama masa sakitnya, $45 \%$ untuk terapi kuratif dan $21 \%$ untuk terapi paliatif. ${ }^{2}$ Bila dibuat perhitungan maka penderita kanker baru di Indonesia yang memerlukan terapi radiasi lebih kurang 151.800 orang per tahun. Rekomendasi International Atomic Agency untuk tiap 500 pasien dapat dilayani oleh 1 pesawat radiasi sehingga diperlukan 303 pesawat linear accelerator atau Cobalt. Sementara itu di Indonesia hanya ada 21 pusat radiasi dan yang aktif hanya 20 pusat radiasi dengan 34 pesawat radiasi, sehingga kapasitas pelayanan kurang memadai. Merujuk pada standar IAEA yang yang menyatakan bahwa setiap satu tenaga dokter spesialis onkologi radiasi seharusnya melayani 250 pasien kanker per tahun maka dibutuhkan 607 dokter spesialis onkologi radiasi, sementara di Indonesia jumlah dokter spesialis onkologi radiasi sangat kurang. ${ }^{3}$ Hal tersebut terjadi karena pelayanan terapi radiasi memerlukan alat yang padat teknologi dan biaya tinggi. Selain itu pendidikan onkologi radiasi pada awalnya merupakan lanjutan dari spesialis radiologi sehingga memerlukan waktu pendidikan yang relatiflama. Sejak diresmikannya pembentukan perhimpunan dan kolegium onkologi radiasi pada 21 Agustus 2007, pendidikan dokter spesialis onkologi radiasi dapat langsung dari dokter umum. Perubahan ini diharapkan dapat memecahkan persoalan tersebut.

\section{TUJUAN}

Audit klinis terhadap individu sangat jarang dilakukan terutama dalam bidang onkologi radiasi tetapi hal ini sekarang meningkat penggunaannya di luar negeri terutama dihubungkan dengan resertifikasi. ${ }^{4}$ Sebagai salah satu bidang baru dalam kategori spesialisasi kedokteran, maka metode pembelajaran menggunakan audit klinis yang meninjau secara khusus terhadap perilaku dan kinerja peserta didik onkologi radiasi Indonesia belum pernah dilakukan. Agar mendapatkan hasil yang memuaskan dan demi perbaikan program pembelajaran, maka perlu dilakukan telaah dan penelitian secara langsung kepada para peserta didik yang mengikuti Program Pendidikan Dokter Spesialis Onkologi Radiasi. Selain itu, penelitian ini juga diharapkan dapat mengevaluasi program yang diterapkan. Pada tulisan ini hanya disajikan data sebelum intervensi (To) dan setelah intervensi pembelajaran melalui email (T1)

\section{METODE}

Rancangan formulir audit dibuat berdasarkan penelusuran kepustakaan antara lain dari RANZCR, TCI Singapore dan panduan dari IAEA. 3,4,5,6,7,8,9,10,11,12.13 
Kemudian formulir ini didiskusikan bentuk dan cara pengisiannya dengan dua orang staf pengajar Onkologi Radiasi dan satu orang staf pengajar Fisika Medis di FK UI/RSUPNCM dan dilakukan perbaikan seperlunya. Setelah formulir audit klinis disepakati maka penelitian ini dilakukan untuk mendapatkan persetujuan dari Komite Etik Penelitian FK UI dan Komite Etik Penelitian UGM.

Onkologi Radiasi merupakan bidang ilmu kedokteran yang harus dikerjakan dengan tingkat ketelitian yang tinggi karena pekerjaan dalam bidang Onkologi Radiasi harus dikerjakan oleh suatu tim sehingga penyampaian pesan secara tertulis harus tepat. Formulir dibagi dalam empat bagian yaitu nilai catatan Rumah Sakit terdiri dari 11 butir, nilai rencana pengobatan 12 butir, nilai simulasi dan planning 10 butir dan nilai selama pengobatan 7 butir. Selanjutnya nilai catatan Rumah sakit dan nilai Rencana Pengobatan di gabung menjadi nilai perilaku yaitu kebiasaan peserta didik sehari-hari dalam melakukan pelayanan kesehatan terhadap pasien, hal ini dipengaruhi oleh pengetahuan yang telah dipunyai peserta didik, pengetahuan yang didapat selama belajar (experiential learning), motivasi dan kelengkapan wahana pembelajaran pada departemen tempat peserta

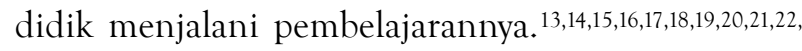
$23,24,25,26,27,28$

Audit Klinis dilakukan terhadap pekerjaan 16 peserta didik yang bertugas di Poliklinik I, II dan III, yang berada pada semester 3,4 dan 5 sejak bulan September 2010 sampai dengan Maret 2011. Evaluasi dengan audit klinis dilakukan oleh peneliti dan seorang dosen Onkologi Radiasi serta kedua nilai digabungkan dan diambil nilai reratanya untuk dilakukan perhitungan. Perhitungan dilakukan dengan menggunakan SPSS versi 17.0.
Penilaian perilaku terdiri dari: (lihat lampiran formulir audit)

1. Penilaian catatan rumah sakit (11 butir). Pada penilaian catatan rumah sakit ini peran peserta didik secara perorangan sangat besar karena peserta didik yang berhadapan langsung dengan pasien dan membuat catatan pekerjaan yang dilakukan.

2. Penilaian rencana pengobatan (12 butir). Semua kasus yang dikerjakan harus atas sepengetahuan dokter penanggungjawab pasien atau harus dikonsulkan pada rapat pagi untuk kasus-kasus baru, jadi ada peran dokter pembimbing.

3. Penilaian selama simulasi dan planning (10 butir). Semua kasus-kasus yang dikerjakan harus dilaporkan dan dimintakan persetujuan dokter pembimbing serta dicatat semua hal yang dikerjakan.

4. Penilaian selama pengobatan (7 butir). Semua kasus yang dikerjakan harus dicatat di catatan medis, pasien yang selesai pengobatan harus dikembalikan kepada dokter pengirim dan dibuat rencana kapan seharusnya pasien harus kembali kontrol.

\section{HASIL DAN PEMBAHASAN}

Didalam naskah ini hanya menyajikan data sebelum intervensi (T0) dan data setelah intervensi (T1). Didapatkan 164 kasus (To) dan 156 kasus (T1) yang dikerjakan 16 peserta didik pada To dan 11 peserta didik pada T1 dengan rentang jumlah kasus 4-17 pada To dan 3 - 34 pada T1 per peserta didik. Perbandingan nilai antara T0 dan T1 dapat dilihat pada Tabel 1 di bawah ini.

Tabel 1. Karakteristik penelitian dan hasil

\begin{tabular}{clcc} 
No & \multicolumn{1}{c}{ Keterangan } & T0 & T1 \\
1 & Jumlah peserta didik & 16 & 11 \\
2 & Jumlah kasus yang dikerjakan & 164 & 156 \\
3 & Rerata kasus dan rentang kasus/peserta didik & $9(4-18)$ & $14(3-34)$ \\
4 & Jumlah peserta didik yang dapat dilakukan t test & 11 & 11 \\
5 & Rerata nilai catatan rumah sakit & 1,87 & 1,95 \\
6 & Rerata nilai rencana pengobatan & 1,98 & 2 \\
7 & Rerata nilai simulasi \& planning & 1,89 & 1,97 \\
8 & Rerata nilai selama pengobatan & 1,97 & 1,99 \\
9 & Rerata nilai perilaku & 1,93 & 1,98 \\
\hline
\end{tabular}


Peserta didik yang diaudit pada TO adalah 16 orang tetapi pada $\mathrm{T} 1$ hanya 11 orang sehingga perhitungan $t$ test hanya bisa dilakukan pada 11 peserta didik dengan

hasil seperti Tabel 2 dibawah ini.

Tabel 2. Hasil penilaian catatan rumah sakit, rencana pengobatan, simulasi dan planning serta selama pengobatan sebelum intervensi dan sesudah intervensi I

\begin{tabular}{lcccccc}
\multicolumn{1}{c}{ Variabel } & $\mathrm{n}$ & Rerata1 & Rerata2 & $\begin{array}{l}\text { Rerata1- } \\
\text { Rerata2 }\end{array}$ & Simpang Baku & Nilai-p \\
$\begin{array}{l}\text { Catatan_RS_sebelum - } \\
\text { Catatan_RS_intervensi1 }\end{array}$ & 11 & 1,87 & 1,95 & $-0,08$ & 0,08 & 0,01 \\
\hline $\begin{array}{l}\text { Rencana_Pengobatan_sebelum - } \\
\text { Rencana_Pengobatan_intervensi } 1\end{array}$ & 11 & 1,97 & 2,00 & $-0,02$ & 0,06 & 0,20 \\
\hline $\begin{array}{l}\text { Simulasi_Planning_sebelum - } \\
\text { Simulasi_Planning_intervenvsi }\end{array}$ & 11 & 1,89 & 1,97 & $-0,07$ & 0,09 & 0,04 \\
\hline $\begin{array}{l}\text { Selama_Pengobatan_sebelum - } \\
\text { Selama_Pengobatan_intervensi1 }\end{array}$ & 11 & 1,97 & 1,99 & $-0,03$ & 0,03 & 0,02 \\
\hline
\end{tabular}

Berdasarkan Tabel 2 dapat dilihat bahwa rerata nilai catatan rumah sakit pada $\mathrm{T} 1$ berubah bermakna setelah intervensi $p=0,008$, sedangkan rencana pengobatan nilainya tidak berubah bermakna karena nilainya sudah baik $\mathrm{p}=0,202$. Sementara itu nilai simulasi dan planning berubah bermakna dengan $\mathrm{p}=0,036$ demikian juga nilai selama pengobatan berubah bermakna dengan nilai $\mathrm{p}=0,019$.

Nilai perilaku adalah pengabungan antara nilai catatan rumah sakit, nilai rencana pengobatan nilai simulasi dan planning dan nilai selama pengobatan. Lihat Tabel 3 di bawah ini.

Tabel 3. Perilaku sebelum intervensi dan setelah intervensi I

\begin{tabular}{ccccccc} 
Variabel & N & Rerata1 & Rerata2 & Rerata1-Rerata2 & Simpang Baku & Nilaip \\
$\begin{array}{c}\text { Rerata_Perilaku_sebelum } \\
\text { Rcrata_Pcrilaku_intcrvcnsi1 }\end{array}$ & 11 & 1,92 & 1,97 & $-0,05$ & 0,05 & 0,01 \\
\hline
\end{tabular}

Nilai rata-rata perilaku pada T0 adalah 1,92 sedangkan pada $\mathrm{T} 1$ adalah 1,97 dengan simpang baku 0,051 terdapat $p=0.006$. Perubahan yang terjadi pada perilaku dapat perubahan yang bermakna setelah intervensi dengan

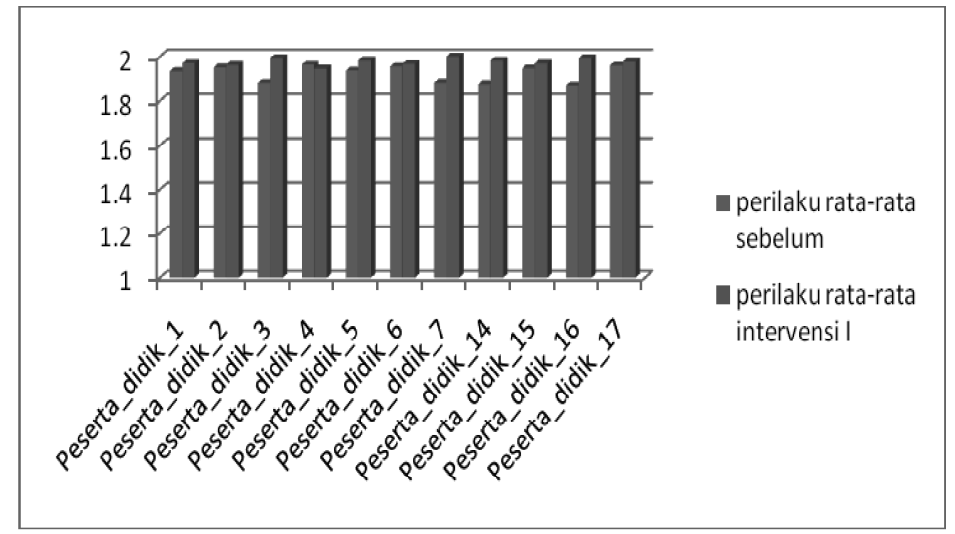

Grafik 1. Perilaku sebelum intervensi dan setelah intervensi I 
Audit klinis merupakan salah satu cara evaluasi formatif. ${ }^{12,13,18,22,24,25,26,27,28}$ Audit klinis pada penelitian ini merupakan suatu proses pembelajaran untuk memelihara dan bila mungkin meningkatkan kinerja dan perilaku peserta didik Program Pendidikan Dokter Spesialis Onkologi Radiasi. Audit klinis juga harus memakai sistem "no blame policy" atau tidak menyalahkan dan memberikan hasil audit sebagai umpan balik sebagai cara pembelajaran kepada peserta didik. $4,5,6,7,10,12,13,18$, $19,22,27$

Perilaku peserta didik dipengaruhi oleh pengetahuan yang telah dimiliki peserta didik, pengetahuan yang didapat selama belajar (experiential learning), motivasi dan kelengkapan wahana pembelajaran pada departemen tempat peserta didik tersebut belajar. Keberhasilan pendidikan klinis tergantung pada pembimbing klinis, peserta didik itu sendiri, wahana pendidikan dan program pendidikan yang dirancang. ${ }^{20}$ Penelitian ini bertujuan melakukan pembelajaran dengan menggunakan audit pekerjaan peserta didik melalui catatan medis yang dikerjakannya.

Perubahan perilaku terjadi antara audit klinis periode I ke periode II dan secara statistik perubahan ini bermakna $p=0,00027$. Bila ditelaah lagi maka komponen yang bermakna meningkat adalah perbaikan terhadap pembuatan catatan rumah sakit. Rentang nilai perilaku pada penelitian ini antara $37.16 \%$ sampai $100 \%$ jadi sebanding dengan hasil yang didapatkan dari penelitian Shakespeare di Australia, New Zealand dan Singapore yang mendapatkan rata-rata perilaku dokter Onkologi Radiasi dan Residen dengan rentang nilai 30\% sampai $100 \%{ }^{7}$

Sementara itu penilaian kelompok simulasi dan planning serta kelompok selama pengobatan, peserta didik bekerja sendiri dan mengatasi masalah di poliklinik secara mandiri. Peserta didik berhubungan langsung dengan pasien dan melakukan penatalaksanaan sesuai standar prosedur yang telah ditentukan terhadap pasien berdasarkan kompetensinya serta tentu saja semua kasus dibicarakan dalam pertemuan rutin dengan staf pengajar setiap minggunya dimana hal ini dapat dilihat sebagai salah satu audit internal. Nilai peserta didik juga berubah secara bermakna setelah intervensi dengan nilai $\mathrm{p}=0.01$. Rentang nilai antara $23,17 \%$ sampai $100 \%$ dan nilai rerata seluruh peserta didik juga baik antara 96\%sampai 98\% bila dibandingkan dengan penelitian Shakespeare yang dilakukan pada Dokter Onkologi Radiasi yang telah bekerja sebagai CPD (Continuing Profesional Development) rentang nilainya antara $98-100 \% .{ }^{4,6,7,10,13} \mathrm{Hal}$ ini sesuai dengan pendapat Ruedy bahwa kinerja akan meningkat bila pengetahuan dan kompetensinya meningkat. ${ }^{28}$

\section{KESIMPULAN}

Audit klinis dan umpan balik melalui surat elektronik secara personal pada peserta didik Onkologi Radiasi dapat meningkatkan perilaku peserta didik secara bermakna.

\section{UCAPAN TERIMA KASIH}

Ucapan terimakasih kepada Prof dr. HM. Djakaria yang membantu dalam cara pembuatan tool audit serta DR.dr. Sri Mutya Sekarutami, Ibu Sri Suendah M.Sc yang membantu pelaksanaan penelitian ini.

\section{DAFTAR PUSTAKA}

1. Department of Health Service Provision-World Health Organization. Quality and accreditation in health care services: a global review [document on the internet]. WHO Geneva; 2003. Available from:http:// www.who.int/hrh/documents/en/quality_ accreditation.pdf

2. American Society for Radiation Oncology. Fast fact data of cancer [document on the internet]. ASTRO; 2007 [cited 2008 March 16]. Available from:https:/ /www.astro.org.

3. Quality Assurance Team for Radiation Oncology (QUATRO). Comprehensive audits of radiotherapy practices: a tool for quality improvement [document on the internet]. International Atomic Energy Agency; 2007. Available from:http://www-pub.iaea.org/ MTCD/publications/PDF/Pub1297_web.pdf.

4. Shakespeare TP, Back MF, Lu JJ, Lee KM, \& Mukherjee RK. External audit of clinical practice and medical decision making in a new Asian oncology center: results and implications for both developing and developed nations. Int J Radiation Oncology Biol Phys. 2006;64(3):941-7.

5. Brundage MD, Dixon PF, Mackillop WJ, Shelley WE, Hayter CR, et al. A real-time audit of radiation therapy in a regional cancer center. Int J Radiation Oncology Biol Phys. 1999;43(1):115-24.

6. Leong CN, Shakespeare TP, Mukherjee R, Back MF, Lee KM, Lu JJ, Wynee CJ, Lim K, Tang J, Zhang X. 
Efficacy of an integrated continuing medical education (CME) and quality improvement (QI) program on radiation oncologist $(\mathrm{RO})$ clinical practice. Int J Radiation Oncology Biology Physics. 2006;66:145760.

7. Shakespeare TP, Mukherjee RK, Lu JJ, Wynne CJ, Kumar MB, Back MF. A comparison of RANZCR and Singapore-designed Radiation Oncology practice audit instruments: how does reproducibility affect future approaches to revalidation? Australas Radiol. 2004; 48:195-203.

8. Zissiadis Y, Harper E, Harper C. Development of a clinical chart audit program. Australasian Radiology. 2006;50:349-54.

9. Esik O, Seitz W, Lovey J, Knocke TH, Gaudi I, Nemeth G, et al. External audit on the clinical practice and medical decision-making at the departments of radiotherapy in Budapest and Vienna. Radiotherapy and Oncology. 1999;51(1):87-94.

10. Shakespeare TP, Back MF, Lu JJ, Wynne CJ, Bloomfield L. Design of an internationally accredited radiation oncology training program incorporating novel educational models. Int J Radiat Oncol Biol Phys. 2004;59(4):1157-62.

11. Toohey J, Shakespeare TP, Morgan G. The RANZCR 2006 peer review audit instrument. Journal of Medical Imaging and Radiation Oncology. 2008;52(4):403-13.

12. Beck DE. Performance-based assessment: using preestablished criteria and continuous feedback to enhance a student's ability to perform practice tasks. Journal of Pharmacy Practice. 2000;XIII(5):347-63.

13. Shakespeare TP, Muhkerjee R, Rahul K, Lu JJ, Lee KM, Back MF. Evaluation of an audit with feedback continuing medical education program for radiation oncologists. J Cancer Education. 2005;20:216-21.

14. Gray J. Changing physician prescribing behavior. Can J Clinical Pharmacology. 2006;131:e81-e82.

15. Robertson N, Baker R, Hearnshaw H. Changing the clinical behavior of doctors: a psychological framework. Quality in Health Care. 1996;5:51-4.

16. Goulet F, Jacques A, Gagnon R, Racette P, Sieber W. Assessment of family physicians' performance using patient charts: interrater reliability and concordance with chart-stimulated recall interview. Eval Health Prof. 2007;30(4):376-92.
17. Rahayu GR. Assessment methods for measuring clinical competence: review on psychometric properties. Jurnal Pendidikan Kedokteran dan Profesi Kesehatan Indonesia. 2005;1: 25-38.

18. Grant W. Education assessment: designing assessments to inform and improve student performance. San Francisco: Jossey-Bass; 1998.

19. Nancy Y, Jacobs L, Martinez ED, Budiger SC. Improved surgeon performance in clinical trial: an analysis of quality assurance audits from the American college of surgeons oncology group. J Am Col Surgical. 2006;203:269-76.

20. Emilia O. Kompetensi dokter dan lingkungan belajar klinik di rumah sakit. Yogyakarta: Gadjah Mada University Press; 2008.

21. Epstein RM. Assessment in medical education. The New Journal of Medicine. 2007;356: 387-96.

22. Prihatiningsih TS. Konsep dasar sistem penjaminan mutu. Makalah pada Post Simposium Workshop Peningkatan Mutu Pendidikan Klinik Pada Program Pendidikan dan Program Pendidikan Dokter Spesialis/Sub Spesialis; 2008 Nov 25-26; Yogyakarta.

23. Scholle SH, Roski J, Dunn DL, Adams JL, et al. Availability of data for measuring physician quality performance. Am J Manage Care. 2009;15(1):67-72.

24. Tinsley JA. An education intervention to improve residents' inpatient charting. Academic Psychiatry. 2004;28:136-9.

25. Trowbridge R, Weingarter S. Educational techniques used in changing provider behavior [document on the internet]. Agency for Healthcare Research and Quality; 2007 [cited 2008 Dec 27]. Available from:http://www.ahrq.gov/clinic/ptsafety/ chap54.htm

26. Van der Vleuten CP, Schuwirth LW. Assessing professional competence: from methods to programmes. Med Educ. 2005;39:309-17.

27. Weiss KB, Wagner R. Performance measurement through audit, feedback, and profiling as tools for improving clinical care. Chest. 2000;118:53S-8S.

28. Ruedy J. Assessing student-clinical competence versus performance [document on the internet]. [cited 2010 Oct 10]. Available from:http://web.imu.edu.my/ ejournal/approved/eJournal_1.1_15-21.pdf 


\section{Lampiran.}

FORM AUDIT KLINIK UNTUK SUBJEK

(Peserta Program Dokter Spesialis Onkologi Radiasi Indonesia)

\begin{tabular}{|c|c|c|}
\hline \multicolumn{3}{|c|}{ IDENTITAS AUDITEE } \\
\hline Nama Petugas & Penyeleksi: & Auditor: \\
\hline \multicolumn{3}{|l|}{ No. identitas catatan medis pasien } \\
\hline \multicolumn{3}{|l|}{ Nama PPDS/ kode initial } \\
\hline \multicolumn{3}{|l|}{ Tanggal rujukan ke Radioterapi } \\
\hline \multicolumn{3}{|l|}{ Tanggal Simulasi } \\
\hline \multicolumn{3}{|l|}{ Tanggal TPS selesai } \\
\hline \multicolumn{3}{|l|}{ Tanggal pelaksanaan radiasi } \\
\hline \multicolumn{3}{|l|}{ Tanggal selesai radiasi } \\
\hline \multicolumn{3}{|l|}{ Letak tumor primer/ ICD 0/ ICD 10} \\
\hline Stadium & & TNM atau yang lain \\
\hline Pengobatan yang dilakukan & & Radikal / Paliatif / Benign \\
\hline \multicolumn{3}{|l|}{ Kombinasi dengan sensitizer } \\
\hline Pernah radiasi di tempat yang sama & & Ya / Tidak \\
\hline Audit dilakukan pada saat & Sebelun & $\begin{array}{l}\text { n radiasi/sedang radiasi/selesai } \\
\text { radiasi/tidak diradiasi }\end{array}$ \\
\hline Apakah diberikan umpan balik? & & Ya/ Tidak \\
\hline
\end{tabular}

\begin{tabular}{|c|c|c|c|c|}
\hline No & $\begin{array}{c}\text { Kriteria Perilaku } \\
\text { (Kriteria 1-26) }\end{array}$ & $\begin{array}{l}\text { Catatan } \\
\text { sangat } \\
\text { lengkap } \\
\text { (2) }\end{array}$ & $\begin{array}{l}\text { Catatan } \\
\text { kurang } \\
\text { lengkap } \\
\text { (1) }\end{array}$ & $\begin{array}{c}\text { Tidak ada } \\
\text { catatan } \\
\text { (0) }\end{array}$ \\
\hline \multicolumn{5}{|c|}{ Catatan dari Rumah Sakit atau Departemen } \\
\hline 1. & Catatan riwayat penyakit pasien & & & \\
\hline 2. & Catatan pemeriksaan fisik & & & \\
\hline 3. & Dokumen letak tumor primer adalah benar dan ada & & & \\
\hline 4. & Dokumen histologi adalah benar dan ada & & & \\
\hline 5. & Relevan imaging daerah yang diradiasi & & & \\
\hline 6. & Dokumen Stadium tumor & & & \\
\hline 7. & Dokumen rasional/ alasan untuk radioterapi & & & \\
\hline 8. & Catatan pengobatan yang dilakukan sebelumnya & & & NA \\
\hline 9. & Diskusi mengenai risiko dan/ atau dokumen informed concern & & & \\
\hline 10. & Surat atau catatan dari dokter yang merujuk & & & \\
\hline 11. & Surat untuk dokter yang mengirim & & & \\
\hline
\end{tabular}




\begin{tabular}{|c|c|c|c|}
\hline \multicolumn{4}{|c|}{ Rencana Pengobatan } \\
\hline 12. & Adanya legitimasi nama pasien & & \\
\hline 13. & Daerah radiasi yang spes ifik & & \\
\hline 14. & $\begin{array}{l}\text { Adanya catatan jelas mengenai "Kiri" atau "Kanan" untuk organ } \\
\text { yang tidak tunggal }\end{array}$ & & NA \\
\hline 15. & Modalitas radiasi \& energi tiap fase & $\mathrm{X}$ & \\
\hline 16. & Indikasi untuk pengobatan & $\mathrm{X}$ & \\
\hline 17. & Tujuan pengobatan (radikal vs paliatif) & $\mathrm{x}$ & \\
\hline 18. & Dosis total yang spesifik & $\mathrm{X}$ & \\
\hline 19. & Dosis per fraksi yang spesifik & $\mathrm{X}$ & \\
\hline 20. & Titik dosis RT yang spesifik & $\mathrm{x}$ & \\
\hline 21. & Jumlah fraksi/ hari yang spesifik untuk semua fase & $\mathrm{x}$ & \\
\hline 22. & Jumlah fraksi/minggu yang spesifik untuk semua fase & $\mathrm{X}$ & \\
\hline 23. & Rancangan dosis ditandatangani dan di beri tanggal & $\mathrm{X}$ & \\
\hline \multicolumn{4}{|c|}{ Kinerja (24-40) } \\
\hline \multicolumn{4}{|c|}{ Simulasi dan Planning } \\
\hline 24. & Ukuran separasi tubuh pasien & $\mathrm{x}$ & \\
\hline 25. & $\begin{array}{l}\text { Legitimasi nama pasien ada pada simulasi/VP/Film/Gambar } \\
\text { elektronik }\end{array}$ & $X$ & \\
\hline 26. & Gambar simulasi ditandatangani dan diberi tanggal oleh dokter & $\mathrm{X}$ & \\
\hline 27. & Isodose plan ditandatangani dan diberi tanggal oleh dokter & & NA \\
\hline 28. & VP film ada pada pertama radiasi dan tiap perubahan lapangan & $\mathrm{X}$ & \\
\hline 29. & Dibuat foto lapangan radiasi di tubuh pasien & $X$ & \\
\hline 30. & Cakupan volume target (tumor primer + kgb) & & NA \\
\hline 31. & Dosis pada organ kritis/ICRU $50 \& 60$ & & NA \\
\hline 32. & Dosis total untuk tiap -tiap volume & & NA \\
\hline 33. & QA monitor unit (linac)/ waktu radiasi $\left(\mathrm{Co}^{60}\right)$ & & \\
\hline \multicolumn{4}{|c|}{ Selama Pengobatan } \\
\hline 34. & Catatan bahwa pasien dilihat oleh dokter setiap 5 kali radiasi & & \\
\hline 35. & Perubahan volume radiasi, simulasi ulang & $\mathrm{X}$ & NA \\
\hline 36. & Perubahan dosis, QA ulang & $x$ & NA \\
\hline 37. & Catatan akhir radiasi & & \\
\hline 38. & Catatan rencana follow up & & \\
\hline 39. & Protokol klinik & & \\
\hline 40. & Penelitian & & \\
\hline
\end{tabular}

